\title{
ATIVISMO NO ENSINO DE INGLÊS: APRENDENDO EM REDE
}

Eloisa Fatima Figueiredo Semblano Gonçalves Maria Luiza Magalhães Bastos Oswald Carla Sena dos Santos Pinto ${ }^{(*)}$

\section{INTRODUÇÃO}

As tecnologias da informação e da comunicação vieram mudar o mundo. Nos últimos anos, de maneira cada vez mais rápida, tem sido possível observar que as tecnologias "delineiam novas formas de relações: econômicas, sociais, profissionais, políticas, trazendo novos contornos à sociedade" (SANTOS e WEBER, 2013, p. 43). Tal mudança não se deu apenas na relação homemmáquina, mas, sobretudo nas relações entre os sujeitos. Se antes a comunicação se dava em pequena escala e de forma interpessoal, com o crescimento das redes de comunicação via internet, o intercâmbio de subjetividades passa a se dar numa escala de comunicação de massa, em que o acesso à informação se torna globalizado. Modificam-se, a partir de então, as formas de pensar e de agir das sociedades, tendo em vista que se expandem espaços e tempos e passamos a nos comunicar numa dinâmica diferente: a dinâmica da comunicação em rede.

Sem podermos negar o quanto mudamos na forma de nos comunicarmos, nos relacionarmos, produzirmos, consumirmos e nos informarmos, é de fundamental importância observar que "as tecnologias são artefatos culturais produzidos pelo próprio homem, então, a relação é híbrida, os sujeitos se constituem produzindo e na relação com essas tecnologias" (SANTOS, 2011, online). Portanto, não é mais possível pensarmos a sociedade de forma separada da tecnologia ou compreender o ser humano sem que se pense em suas relações cotidianas nas cidades e no ciberespaço, relações a partir das quais se formam suas subjetividades, tendo em vista que "as tecnologias digitais em rede não são atores autônomos, separados da sociedade e da cultura na qual estamos imersos" (SANTOS e WEBER, 2013).

\footnotetext{
${ }^{(*)}$ Eloisa S. Gonçalves. Mestre em Educação pela Universidade do Estado do Rio de Janeiro (ProPEd / UERJ). Doutoranda pelo UniversidadeFederal Fluminense (PPGMC/UFF). Orcid: 〈https://orcid.org/0000-0002-4360-829X>. E-mail eloisasemblano@gmail.com.
}

Maria Luiza Oswald. Doutora em Educação pela Pontifícia Universidade Católica do Rio de Janeiro (PUC-Rio). Orcid: <https://orcid.org/0000-0001-7742-3261?lang=en>. E-mail moswalduerj@yahoo.com.br.

Carla Santos Pinto. Mestre em Educação pelo ProPEd/UERJ. Orcid: <https://orcid.org/0000-0002-3751-5388>. Email carlasenas@gmail.com. 
Em se tratando da educação e sendo a escola parte da sociedade, a chegada das tecnologias de informação e comunicação no âmbito escolar evidencia desafios e mudanças relacionados aos espaços-tempos que o uso destas provoca nas práticas cotidianas educacionais, ressaltando que a mobilidade e a ubiquidade propiciadas pela disseminação dos dispositivos móveis e aplicativos na contemporaneidade vêm potencializar novas formas de ensinar e aprender.

Este artigo é fruto de pesquisa desenvolvida com o objetivo de conhecer as experiências de jovens de uma escola estadual de Niterói com a língua inglesa, mediadas pelas tecnologias digitais. As descobertas da pesquisa revelam que o uso de aplicativos para dispositivos móveis, quando utilizados como recurso pedagógico, auxiliam no desenvolvimento dos processos de ensinar e aprender, propiciando a autoria e potencializando a tessitura colaborativa de conhecimentos entre professores e alunos.

\section{TESSITURA DE CONHECIMENTOS NA CULTURA CONTEMPORÂNEA}

As reconfigurações socioculturais vivenciadas pelos jovens na contemporaneidade e que determinam seus modos de subjetivação estão intimamente interligadas aos princípios da cibercultura estabelecidos por Lemos (2007), já que suas vivências com os artefatos digitais, principalmente os aparelhos móveis, são parte de sua cultura cotidiana. Compreender os princípios da cibercultura nos permite o entendimento das reconfigurações culturais dos jovens contemporâneos, bem como o território digital informacional e os impactos socioculturais que as tecnologias de informação e comunicação trouxeram ao mundo contemporâneo.

Lemos (2007) estabelece três princípios da cibercultura que corroboram com a ideia de organização horizontal em rede $e^{1}$ proposta por Pretto (2006): a liberação do polo da emissão, o princípio de conexão em rede e a consequente reconfiguração sociocultural a partir de novas práticas produtivas e recombinatórias ${ }^{2}$. Para Lemos (2007) “a cibercultura instaura uma estrutura midiática ímpar na história da humanidade” (p. 39), ou seja, apesar de toda formação cultural ter

\footnotetext{
${ }^{1}$ Nelson Pretto (2006) destaca em seu texto Tecnologias e Novas Educações que desde as sociedades mais antigas a humanidade está acostumada a se organizar de forma hierárquica e vertical, o que ele chama de organização vertical de comando. Entretanto, a partir do processo de globalização, surge uma nova forma de organização e distribuição de produtos, vendas e serviços, fazendo com que não mais tenhamos apenas uma referência de comando no topo, mas passando a ter uma referência mais global, ao que o autor chama de organização horizontal em rede. Pretto (2006) ressalta que organizações em rede acontecem antes do advento da Internet, porém esta veio trazer suporte propício para o desenvolvimento deste tipo de organização.

${ }^{2} \mathrm{O}$ termo recombinatório se refere ao fato de que a cibercultura instaura uma estrutura em que qualquer indivíduo pode a partir de então produzir, publicar, adicionar e colaborar em rede, reconfigurando assim a indústria cultural de massa.
} 
sido sempre uma recombinação de elementos, pela primeira vez, é possível a todo e qualquer indivíduo produzir e publicar informações em tempo real, adicionar e colaborar em rede com outros, o que faz com que a indústria cultural contemporânea seja reconfigurada com tamanha rapidez e alcance nunca antes vistos. O que faz de fato diferença na cibercultura, portanto, não é a recombinação dos elementos culturais, mas a velocidade, a forma de disseminação e a amplitude dos espaços e tempos que o ciberespaço proporciona.

A liberação do polo de emissão é o princípio básico da cultura pós-massiva e a principal característica da cibercultura (LEMOS, 2007). Se antes, na cultura massiva, tínhamos apenas como polos de emissão as mídias de massa, como emissoras de TV e rádio, revistas, jornais, entre outras, na cibercultura pessoas comuns passam a ter a possibilidade de produzir e emitir suas próprias informações. Cada um passa a ser produtor e emissor de conteúdos, através de diferentes formatos midiáticos, como fotografias, podcasts, vídeos, blogs, desenvolvimento de softwares, por exemplo, e de forma planetária. Como conclui Lemos (2007), "na cultura pós-massiva, que constitui a atual cibercultura, produzir, fazer circular e acessar cada vez mais informação tornam-se atos quotidianos, corriqueiros, banais" (p. 39). ${ }^{3}$

O segundo princípio da cibercultura estabelecido por Lemos (2007) é o de conexão em rede. Este princípio remete ao compartilhamento das informações e dos conteúdos produzidos, isto é, não basta produzir, é preciso compartilhar esses conhecimentos. Segundo Couto Junior (2012):

(...) é a partir das diferentes possibilidades de navegar no ciberespaço por meio de inúmeras interfaces que muitos jovens vêm rompendo com o polo da emissão e interagindo com outros internautas que podem estar geograficamente dispersos e, ainda sim, conectados entre si pela rede (p. 31).

O terceiro princípio da cibercultura estabelecido por Lemos (2007) talvez seja o que mais diretamente se remeta aos jovens contemporâneos: a reconfiguração sociocultural a partir de novas práticas produtivas e recombinatórias. Este princípio é fundamentalmente resultado dos dois primeiros. A partir do momento que produzimos e compartilhamos conteúdos e informações, passamos a reconfigurar a indústria cultural e as culturas de massa. É a quebra de fronteiras, onde mídias massivas rendem-se em determinados momentos à cultura digital pós-massiva, o que não significa o fim desta indústria massiva. Lemos (2007) sintetiza este terceiro princípio dizendo que

\footnotetext{
3 Texto retirado da transcrição revisada da Conferência ministrada por André Lemos no evento "Territórios Recombinantes", realizado no Instituto Goethe (ICBA), em Salvador, em agosto de 2006. O material embasou a conferência ministrada também por Lemos no I Simpósio Nacional de Pesquisadores em Comunicação e cibercultura, realizado na PUC/SP, em setembro do mesmo ano.
} 
“a cibercultura é essa configuração em que se alternarão processos massivos e pós-massivos, na rede ou fora dela" (p. 40).

De acordo com Santos, Maddalena e Rossini (2016),

A linguagem que surge na cibercultura - hipermídia - a partir da convergência das matrizes sonora, visual e verbal tem como características a plasticidade e a hipertextualidade [...] A multidimensionalidade propiciada pela interligação de computadores em rede permite que percursos sejam construídos de acordo com a necessidade a partir de fragmentos de textos que podem ser associados dinamicamente (hipertexto) (p. 93).

A linguagem hipertextual permite retomarmos a noção de interatividade, no sentido de que o hipertexto permite ao leitor decidir o rumo a seguir na sua viagem pelo ciberespaço, tornando-o flexível. Neste sentido, a cibercultura permite uma reconfiguração dos espaçostempos ${ }^{4}$ e novas formas de produção do conhecimento vão sendo criadas, nas redes, no ciberespaço, num processo que pode ser descrito como "tessitura do conhecimento". Em 2001, Alves e Oliveira cunham o termo "tessitura do conhecimento" buscando compreender o sujeito na sua multidimensionalidade e nas redes que estes vão tecendo ao longo de suas trajetórias, redes estas que, enquanto praticantes culturais, construímos individual ou coletivamente na medida em que vivenciamos experiências práticas e teóricas em diferentes espaçostempos. Nesse sentido Alves (2012) afirma que:

Em seu viver cotidiano, os seres humanos se articulam em múltiplas redes educativas que formam e nas quais se formam - como cidadãos, trabalhadores, habitantes de espaçostempos diversos, criadores de conhecimentos e significações e de expressões artísticas, membros de coletivos vários (famílias, religiões, expressões nas mídias), usuários de processos midiáticos etc. (p. 26).

A ideia de construção do conhecimento, antes vista como uma produção rígida e um processo de aquisição de saberes fechados, passa a ser desconstruída com o conceito forjado por Alves e Oliveira (2001). O termo "tessitura do conhecimento" apresenta-se como uma metáfora da rede, onde diversos fios são trançados e podem ser puxados a todo instante, o que nos leva a compreender que o conhecimento se dá no entrelaçamento das diversas esferas da vida humana enredadas umas às outras.

\footnotetext{
4 As autoras utilizam os termos escritos sem separação para mostrar a importância de superar os limites do modo dicotomizado moderno de pensar.
} 
É nesse contexto que se dá a noção de 'tessitura do conhecimento em rede' e que podemos perceber que a cibercultura vem potencializar as reconfigurações socioculturais e de espaçostempos, como vemos em Santos e Santos (2013):

Com essa noção de rede, o diálogo entre cotidiano e ciberespaço se enriquece. Ao longo de nossa existência vamos trançando vários fios e compondo várias redes, participando de diversas tramas, mergulhando com todos os nossos sentidos no que vamos entendendo ser, a cada momento, a realidade. Vivemos as diferentes esferas da vida humana, sejam elas sociais, afetivas, políticas, individuais ou coletivas, que não se separam quando produzimos conhecimento, estão sempre enredadas umas às outras. Por isso precisamos pensar a criação do conhecimento como um processo de tessitura de conhecimento em rede (p. 50).

A complexidade do sujeito pode ser pensada, portanto, a partir das redes em que estes se enredam em suas práticas cotidianas, potencializadas na contemporaneidade pela cibercultura, não apenas pela multiplicidade de linguagens por ela propiciada, mas também pelo "universo oceânico de informações que a internet abriga, assim como os seres humanos que navegam e alimentam esse universo com suas histórias, seus rastros e suas itinerâncias" (SANTOS e SANTOS, 2013, p. 52).

\section{MOBILIDADE, UBIQUIDADE E CONECTIVIDADE}

$\mathrm{Na}$ primeira fase da web "ciberespaço e cidades eram espaços de comunicação unidirecionais, ou seja, a cidade sedia um ponto fixo para conexão com outro espaço" (SANTOS, 2014, p. 26), mantendo um distanciamento entre eles. Além disso, baseava-se ainda no esquema clássico da informação emissor-mensagem-informação, onde a mensagem era fechada e o receptor apenas podia acessá-la (MARCHAND, 1987, p. 9, apud SANTOS, 2014, p. 27), copiá-la, mas nunca interferir ou interagir com a mesma. A web 2.0 veio transformar o esquema clássico de emissão-recepção, oportunizando aos usuários a possibilidade de maior participação, colaboração e autoria nas redes, através de chats, fóruns, blogs e os softwares de redes sociais. Já a terceira geração da web trouxe um caráter semântico à navegação, possibilitando que as máquinas assumissem atividades antes realizadas manualmente e a organização dos conteúdos acessados de maneira mais personalizada para cada internauta, a partir de pesquisas e comportamentos. Entretanto, foi com o surgimento da mobilidade ubíqua, entendendo ubiquidade "como uma habilidade de comunicação a qualquer tempo e hora, por meio de dispositivos móveis dispersos pelo meio ambiente" (SANTOS e WEBER, 2013, p. 289) que se deu a aproximação entre ciberespaço e cidades. 
Com a evolução dos dispositivos móveis, principalmente dos smartphones, que passaram a permitir a conexão com o ciberespaço através dos sinais digitais 3G / 4G, emergem novas possibilidades e usos antes não propiciados pela imobilidade dos computadores fixos do tipo desktop.

Estas tecnologias potencializam que pessoas distantes fisicamente possam se comunicar em espaços híbridos, conectados por meio de rede móvel, ao mesmo tempo em que se deslocam pelo espaço físico habitado por outros sujeitos, com quem muitas vezes, também interagem simultaneamente (LUCENA; PEREIRA e OLIVEIRA, 2016, p. 109).

Apesar de a comunicação ter sido sempre presente e fundamental na humanidade, estamos vivendo neste século uma mudança não apenas tecnológica, mas na estruturação da organização da sociedade, tendo em vista que os processos híbridos de comunicação, potencializados pela mobilidade, afetam os modos de viver das pessoas.

Neste sentido, mobilidade, ubiquidade e conectividade estão diretamente ligadas às formas de aprender inglês, reveladas pelos sujeitos da pesquisa desenvolvida e a aprendizagem com aplicativos aproxima a escola das subjetividades do jovem contemporâneo, propiciando assim uma aprendizagem mais significativa, como é possível perceber com Samuel (2016), sujeito da pesquisa:

Eu achei a experiência muito legal para os alunos e é uma... como posso dizer, é um pensamento muito criativo que a senhora teve em vir com aplicativos porque nossa nova geração ela tá movida, vamos dizer assim, pelo celular, pelo smartphone, tudo agora é feito no smartphone. Você faz trabalho no smartphone, monta slide no smartphone... virou um vício. Acho até prejudicial para algumas áreas, pros adolescentes, mas beneficia a gente na escola.

Os usos dos aplicativos e do digital em rede propiciam uma aprendizagem mais flexível, onde espaços e tempos são ampliados e ressignificados o que torna a aprendizagem mais significativa e útil. De acordo com Santos e Weber (2013):

O modelo de um sistema de aprendizagem móvel descreve um modo de aprendizagem no qual os alunos podem se mover em diferentes locais físicos e virtuais e, assim, participar e interagir com outras pessoas, informações ou sistemas, em qualquer lugar, a qualquer hora (p. 293).

Se antes dos smartphones era necessária uma diversidade de aparelhos para diversas funções como tirar fotos, filmar, gravar um áudio e mesmo pesquisar nas redes (o que só era possível nos computadores que possuíam uma linha física), nos dias atuais o smartphone se apresenta como um dispositivo no qual há a convergência dessas mídias: a máquina fotográfica, a filmadora, o gra vador 
de áudio e a conexão com o ciberespaço em tempo real e em espaços móveis, todos os recursos disponíveis em um só dispositivo, além de uma infinidade de aplicativos que podem potencializar a criatividade de professores e alunos. Esse contexto contemporâneo nos leva a compreender "que a aquisição de informação, conhecimento e a aprendizagem se dão de formas distintas das de outros tempos, dadas principalmente pela colaboração, interação e conexão" (SANTOS; WEBER, 2013, p. 299). Os aplicativos para dispositivos móveis contam "com a convergência de interfaces e linguagens que permitem produzir, editar e compartilhar em rede" (SANTOS, 2015, p. 138) e permitem nas salas de aula uma aprendizagem mais significativa por se aproximar dos modos de ser e estar dos jovens contemporâneos na sociedade.

As experiências do jovem contemporâneo com os dispositivos móveis e com o uso de aplicativos permitem "o desenvolvimento de habilidades e competências mais flexíveis para a gestão do conhecimento" (SANTOS e WEBER, 2013, p. 57), como se pode observar com Emanuelle na pesquisa:

Eu já vi vídeo aula no YouTube, já cheguei a baixar uma apostila básica de inglês pra me ajudar em algumas coisas e eu sempre uso aplicativos, como o Duolingo, uso o Google Tradutor, vejo séries com legenda. Vou usando o que vou precisando, dependendo do que quero fazer ou saber. E tá tudo na minha mão, no celular.

O uso de aplicativos permite deslocamento e comunicação, uma experiência ubíqua, e desta forma o celular se mostra como um instrumento mediador que propicia a criação, a produção a circulação de signos (SANTOS, 2013), permitindo a busca pela situação, o contexto e o momento oportunos.

\section{APRENDIZAGEM UBÍQUA}

Enquanto professoras-pesquisadoras e compreendendo que os dispositivos móveis, conectados e ubíquos, podem promover uma mudança nas formas de ensinar e aprender, transformando as relações de espaços e tempos e permitindo que o jovem "se movimente carregando, produzindo e cocriando informações e conhecimentos" (SANTOS, 2013, p. 289) e não apenas como forma de consumo de conteúdos e informações, algumas oficinas foram desenvolvidas ao longo da pesquisa com o uso de aplicativos em sala de aula. As oficinas com o uso de aplicativos tiveram como objetivo propiciar práticas pedagógicas que pudessem suscitar novas conversas com os sujeitos, além de enfatizarem os desafios e as dinâmicas que os aplicativos proporcionam em diversos processos de ensino e aprendizagem, na era da conectividade. 
Apresentamos algumas dessas experiências, ressaltando que buscamos, através dessas experiências, articular o aprendizado da língua com aspectos sociais e culturais, além de contextualizar esse aprendizado com outra disciplina, no caso com a Sociologia. Tais experiências objetivaram ainda fazer uso das diversas mídias oferecidas pelos smartphones, como câmera fotográfica, e dos aplicativos, além de pesquisa na web, para produção de conteúdos e a tessitura de conhecimentos.

Cabe aqui ressaltar o papel mediador do professor na realização dos trabalhos, entendendo que, tendo o docente como mediador do conhecimento durante o processo, "os membros do grupo interagem e se influenciam, estabelecem relações sociais, desenvolvem processos para a realização de tarefas com o objetivo de alcançar metas compartilhadas" (SANTOS; CARVALHO; PIMENTEL, 2016, p. 25).

\section{OFICINA I}

Esta experiência consistiu em pesquisarmos o vocabulário referente a termos da Internet e referentes ao uso de computadores e internet como upload, download, login, logout, por exemplo. Utilizando o vocabulário pesquisado, foi solicitado que os alunos utilizassem o aplicativo de QR Code no celular e criassem os códigos para cada uma das palavras estudadas, associando-as aos seus significados. O aplicativo utilizado foi o QR CodeGenerator, baixado no celular dos próprios alunos. Em seguida, foi elaborado um mural interativo, com o qual todos os alunos da escola puderam interagir, baixando leitores de QR Code em seus celulares. Muitos alunos sinalizaram que apesar de já terem visto esse tipo de código em embalagens, não sabiam do que se tratava e qual a sua função, sendo assim atribuíram grande importância ao conhecimento produzido a partir da experiência: "Foi muito bom trabalhar com o celular. Também foi muito importante aprender o significado do aplicativo de QRCode, porque eu até então não conhecia e agora levo isso para a vida" (Samuel). 
Figura 1. Estudantes pesquisando vocabulário para confecção do Mural Interativo.

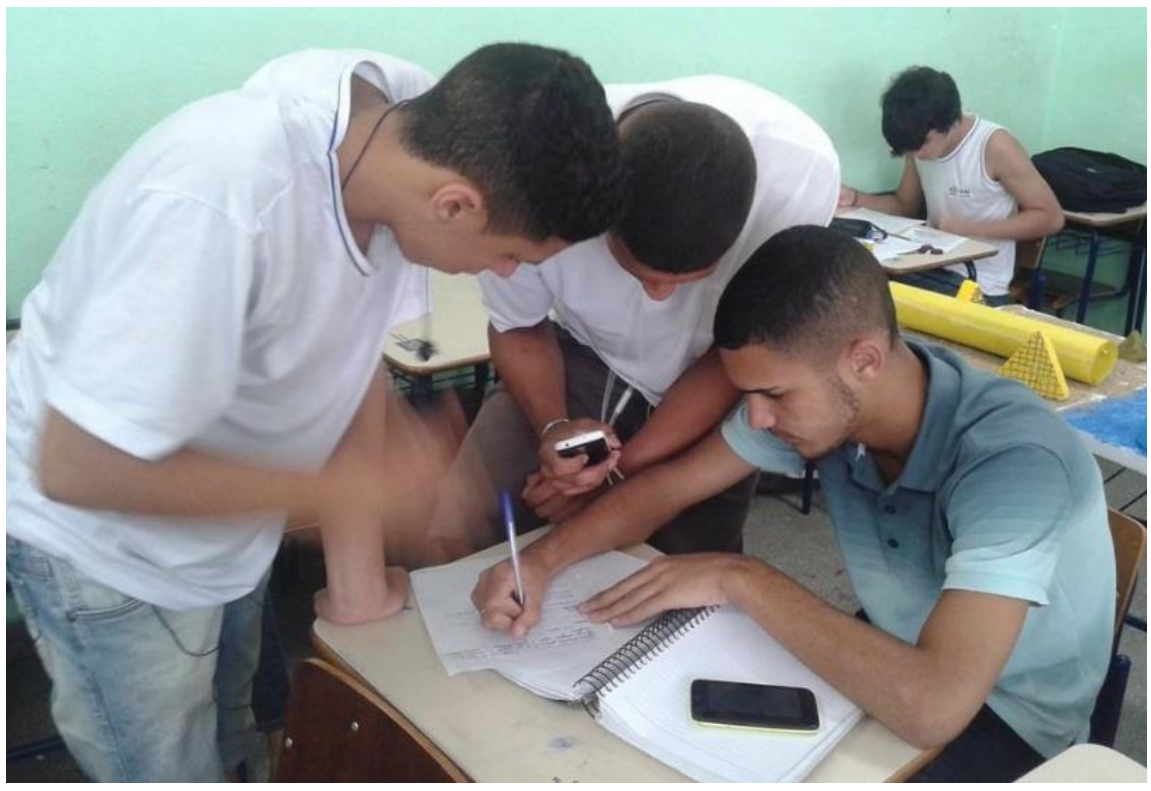

Fonte: Própria, 2016.

Figura 2. Estudantes produzindo QRCodes para confecção do Mural Interativo.

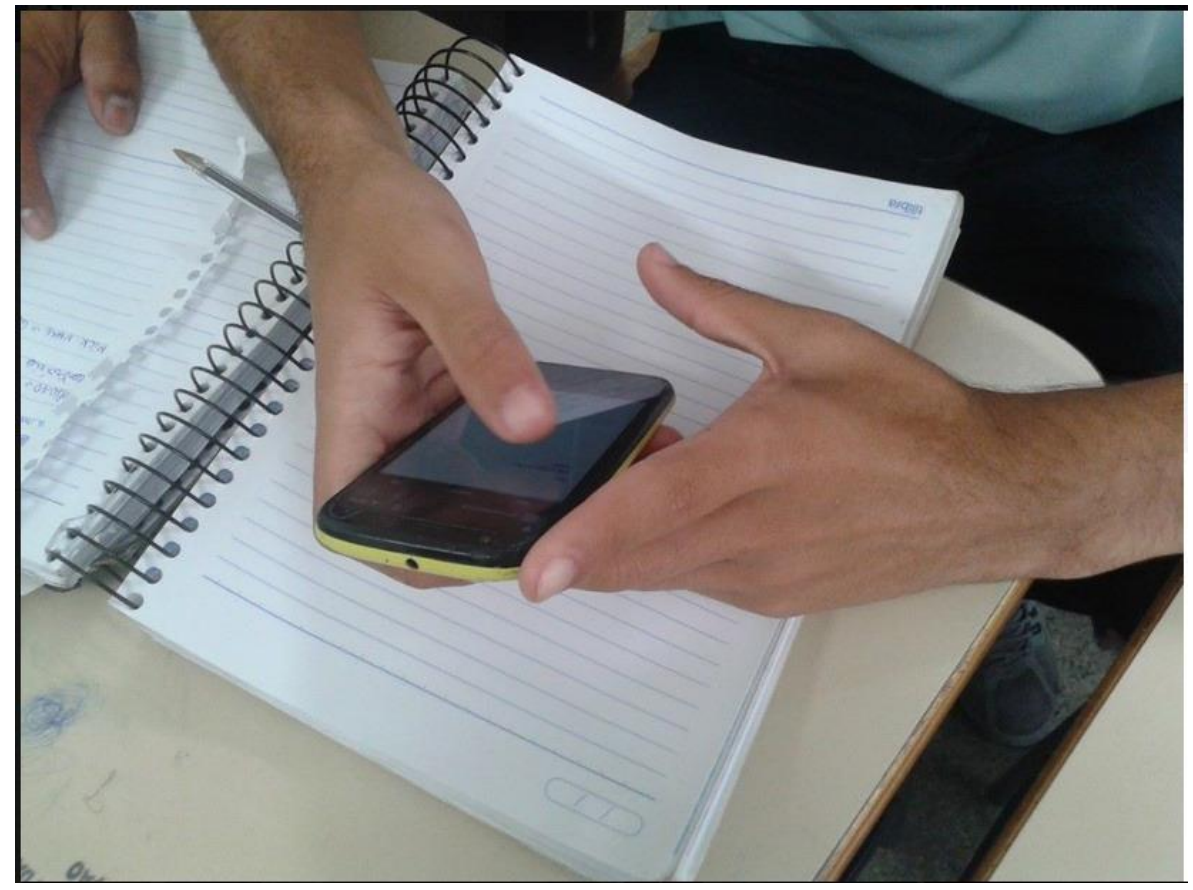

Fonte: Própria, 2016. 
Figura 3. Estudantes organizando material para confecção do Mural Interativo.

Fonte: Própria, 2016.

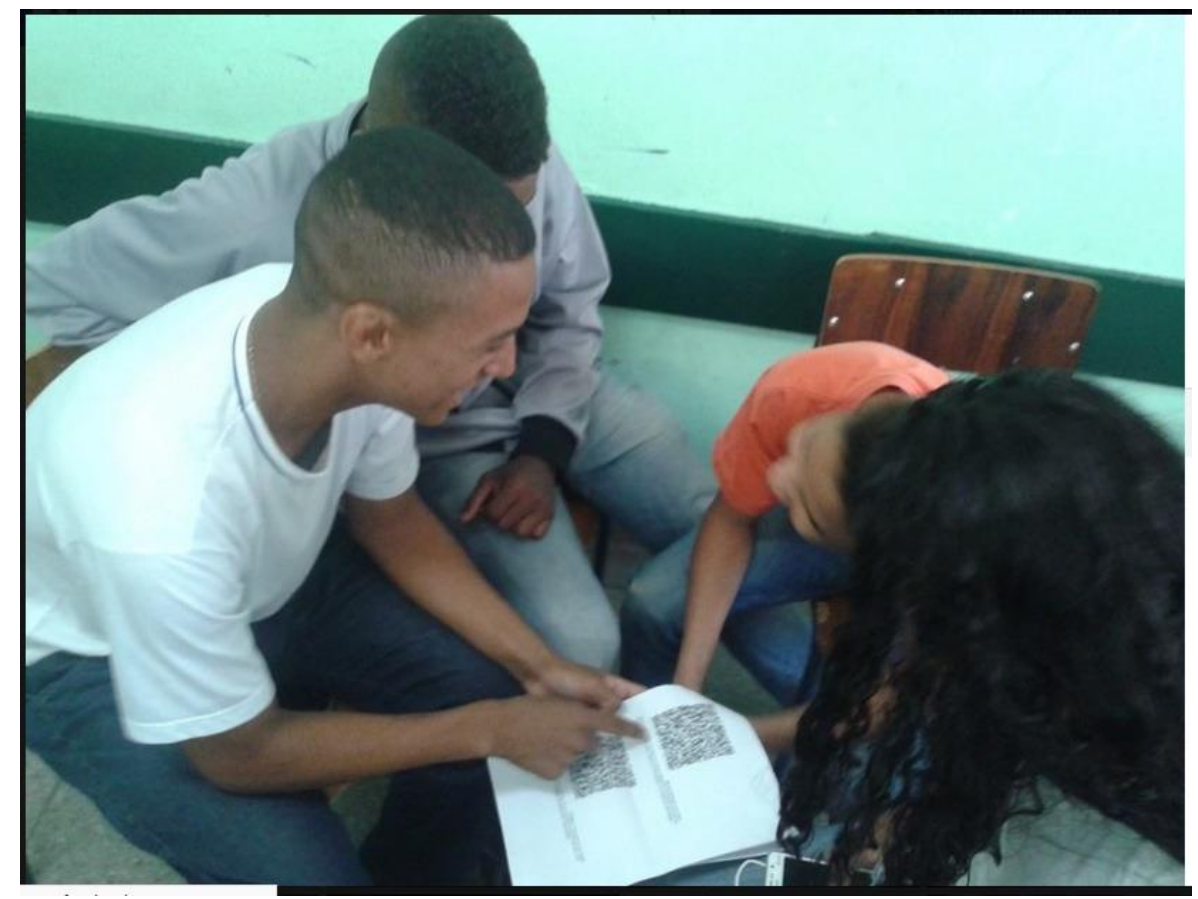

O código Quick Response - QRCode - é um código de barras bidimensional que permite o armazenamento de informações instantâneas de produtos, páginas da internet, imagens, localização e outros conteúdos multimídia. Podem ser criados e acessados através de aplicativos nos dispositivos móveis. Estes códigos permitem a aproximação do espaço físico com o mundo virtual, tendo em vista que podem ser utilizados em exposições, produtos, ou objetos e permitem o acesso a informações disponíveis na internet. No caso deste trabalho, utilizamos o QRCode para acesso a um determinado vocabulário. Entretanto, o resultado foi bastante positivo, como pode ser observado na fala de Thomas:

$\mathrm{Eu}$ fico surpreso assim com alguns professores que trabalham o inglês interagindo com o jovem, sabe? Porque aquele inglês padrão, da sala de aula é muito chato, mas aquele inglês que você vai fazer uma pesquisa, usar um aplicativo [...] Os jovens, eles se sentem muito alienados dentro de sala de aula, sabe? E aí interagir na internet pra aprender o inglês é outro nível.

Como sinalizado por Thomas, esse trabalho teve ótima aceitação e participação dos alunos por ter utilizado um aplicativo no dispositivo móvel em sala de aula e por ter sido um trabalho de pesquisa na internet. Vale ressaltar que por muitas vezes disponibilizamos a internet particular, compartilhando dados pelo roteador wi-fi do celular. A repercussão do trabalho foi muito boa, já que envolveu os demais alunos da escola em virtude do mural interativo que foi montado no corredor principal. 


\section{OFICINA II}

A segunda oficina diz respeito a uma proposta de trabalho feita em conjunto com um professor de sociologia da escola na qual sugerimos aos alunos que escolhessem, dentre os temas trabalhados por aquela disciplina, aquele que mais se aproximasse de suas vivências ou de sua realidade social para que, utilizando os seus dispositivos móveis, montassem um seminário, com slides em inglês e em português e com imagens produzidas também por eles. O seminário deveria ser apresentado em conjunto com o professor de sociologia e dividiríamos a apresentação em dois momentos, onde primeiro apresentariam a temática escolhida e em seguida a apresentação deveria discorrer com base nos slides produzidos em inglês. Seguem as produções que mais nos chamaram a atenção, tanto pela pertinência dos temas abordados, como pela produção das imagens e do conteúdo apresentado por escrito e oralmente. Os alunos utilizaram aplicativos como o Google Tradutor, a câmera fotográfica de seus celulares, além de realizarem a pesquisa do conteúdo abordado na internet em sala de aula. 


\section{Trabalho 1}

Figura 4 - Slides do trabalho sobre Direitos Humanos.
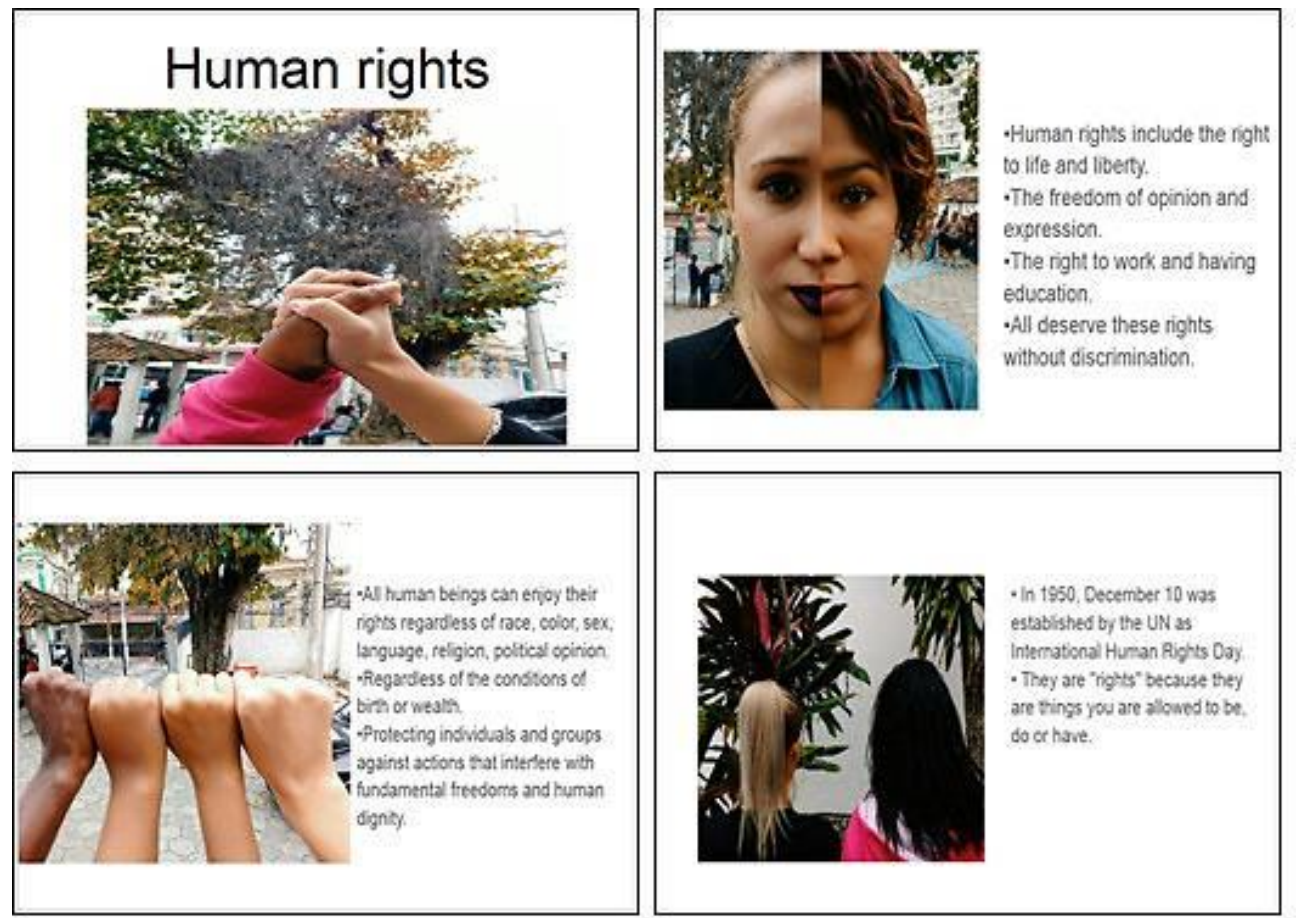

Fonte: Trabalho dos estudantes, 2017.

Neste trabalho sobre Direitos Humanos, as fotos foram produzidas na própria escola e os alunos utilizaram o aplicativo Apresentações Google para a elaboração de seus slides. Os aplicativos foram utilizados em todas as etapas de produção do trabalho, desde a pesquisa, passando pelas fotografias, além da elaboração dos slides em si, mostrando o quanto a aprendizagem ubíqua tem colaborado para a tessitura de conhecimentos na escola, com foco no protagonismo dos alunos. 


\section{Trabalho 2}

Figura 5 - Slides 1 a 4 do trabalho sobre Lixo e Reciclagem.
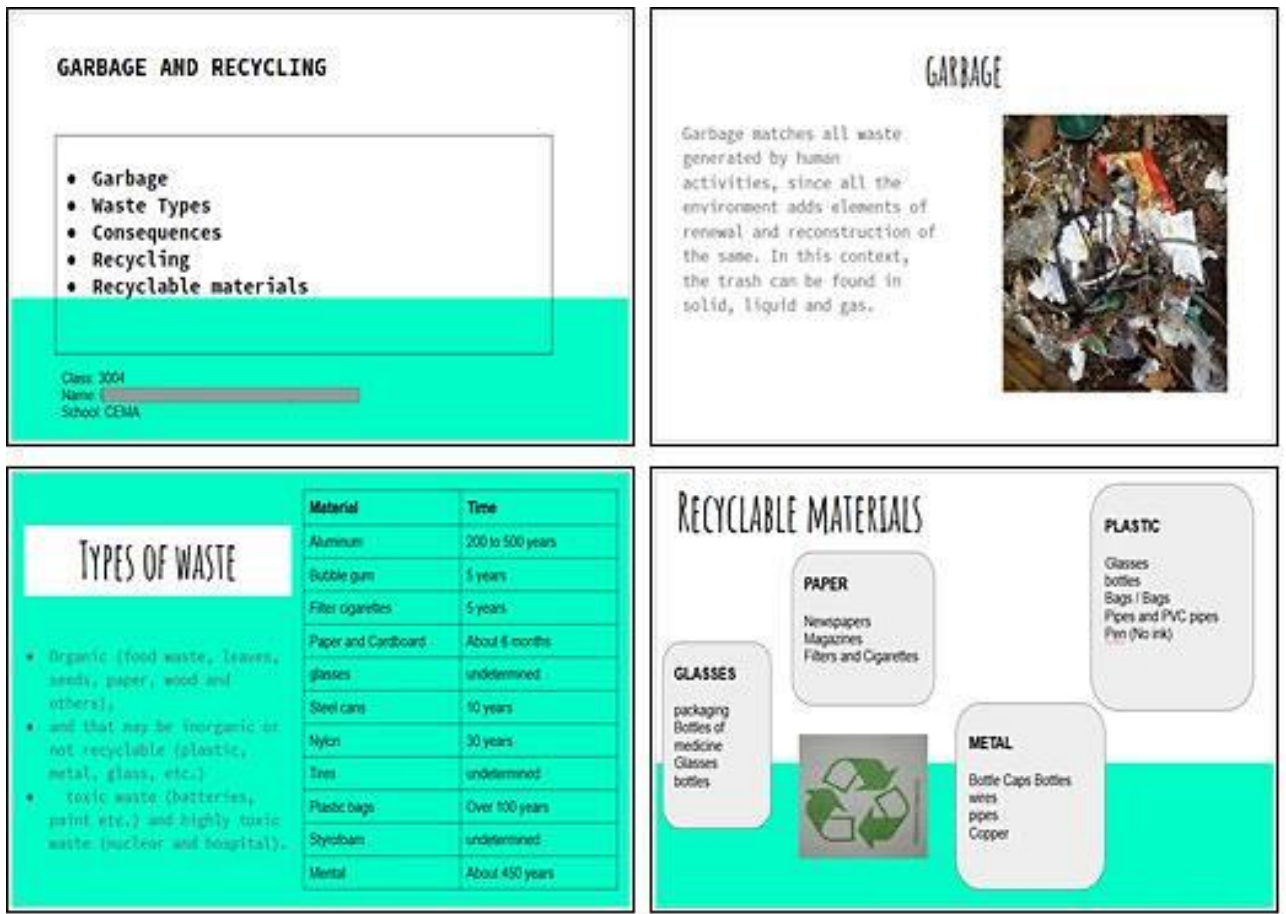

Fonte: Trabalho dos estudantes, 2017.

Figura 6. Slides 5 a 7 do trabalho sobre Lixo e Reciclagem.
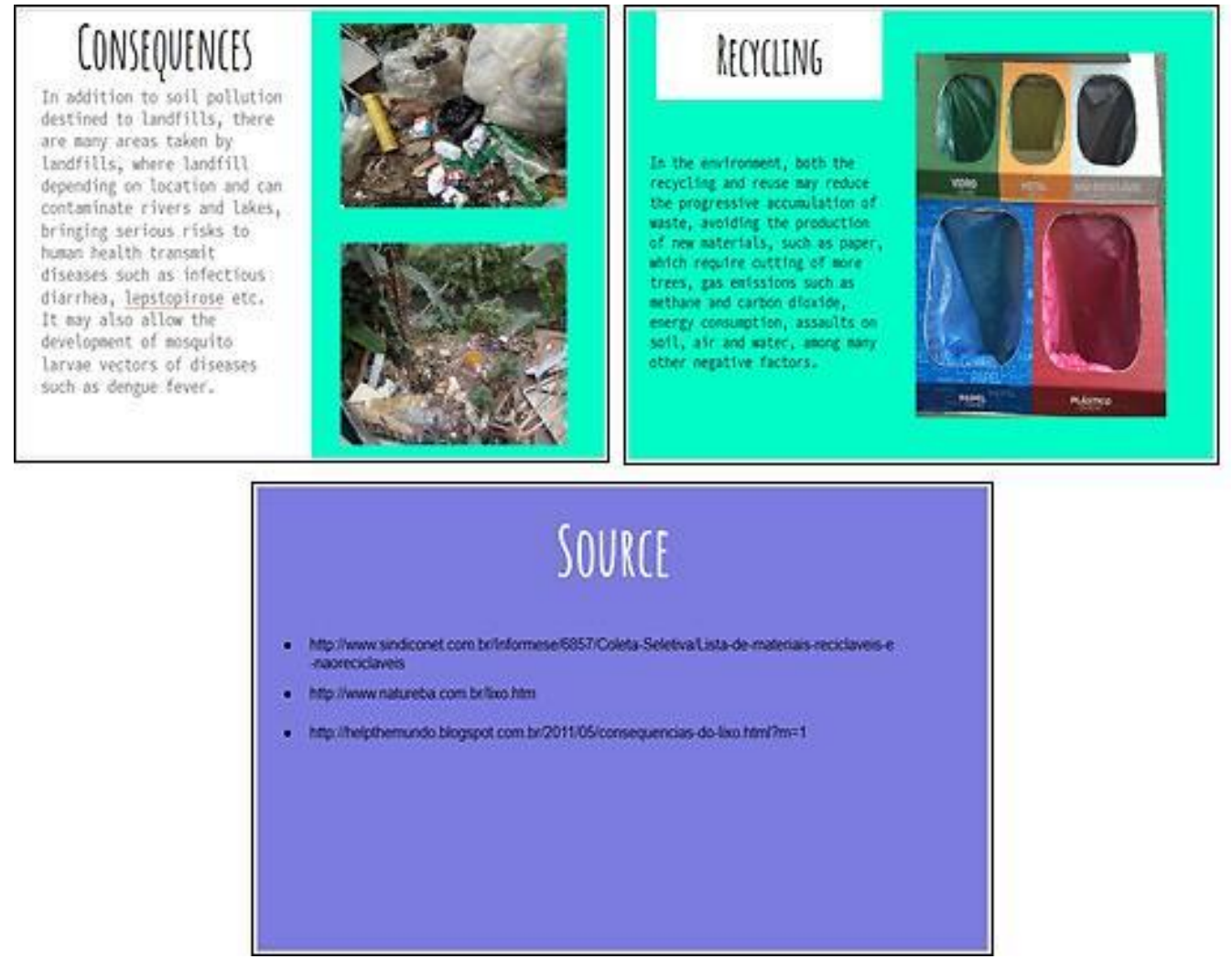

Fonte: Trabalho dos estudantes, 2017. 
Neste trabalho sobre Lixo e Reciclagem, as fotos foram produzidas no caminho para a escola e na comunidade onde os alunos residem. Ao apresentarem seu seminário, os alunos relataram o quanto foi significativo para eles observarem a questão do lixo no seu entorno e como passaram a ter atitudes diferenciadas em relação às questões de saneamento e recolhimento do lixo.

As tecnologias móveis e o uso de aplicativos em sala de aula propiciam um ambiente de colaboração e criação, além de ampliarem os espaços e tempos, favorecendo a tessitura de conhecimentos de forma compartilhada e permitindo a socialização dos aprendizados. Como sinalizam Oliveira e Mercado (2016):

As tecnologias móveis nas aulas [...] podem ampliar as possibilidades de ensino e de aprendizagem, possibilitando aos estudantes escolher seus caminhos e estratégias que possibilitem a construção de conceitos [...] através de uma navegação não-linear, potencializando a mobilidade do conhecimento, a troca de saberes e a construção de sentidos, constituindo como um espaço de informação e interação, ampliando os modos de conhecer, produzir e divulgar conhecimentos, exigindo-se que trabalhem não apenas suas vantagens e/ou desvantagens, mas que trabalhem os conflitos e tensões surgidas, com vistas à busca de soluções (p. 218 e 219).

Apesar de ser visto por muitos professores como uma forma de tirar a atenção do aluno na sala de aula, estas experiências mostraram que se bem orientado e se utilizado na produção de conteúdos, o trabalho com o celular e o uso de diferentes linguagens e o uso de aplicativos potencializam as formas de aprender e ensinar, colaborando para a formação de um sujeito que protagoniza suas aprendizagens, tornando-se mais criativo e crítico. Faz ainda com que este aprendizado ganhe funcionalidade e significado para o aluno, levando-o a compreender melhor seu entorno, sabendo buscar as informações, criar hipóteses, compreender e selecionar aquelas que forem úteis e necessárias à sua experiência.

\section{CONSIDERAÇÕES FINAIS}

O uso das novas tecnologias integrado ao projeto pedagógico, como fator mediador de novas aprendizagens e de tessitura do conhecimento, contribuirá para novas formas de fazer educação. Ensinar tecnologia é uma coisa, ensinar com tecnologia é outra. E é nessa outra perspectiva, do "ensinar com", que o uso das tecnologias digitais em rede se faz fundamental. Importante destacar a relevância do uso de práticas de App_learning como forma de tentar compreender como os jovens contemporâneos imersos no contexto cibercultural utilizam os aplicativos disponíveis nos dispositivos móveis para a produção e o compartilhamento de saberes em espaços e tempos formais 
e não-formais de aprendizagem e protagonizam seus aprendizados. Neste contexto, o uso de aplicativos para o aprendizado vem se destacando, principalmente, entre os jovens por propiciar uma forma de ativismo que privilegia a prática efetiva de transformação da realidade.

As experiências vivenciadas com os jovens pesquisados nos remetem a Lévy (2003) no que concerne ao conceito de inteligência coletiva como "uma inteligência distribuída por toda parte, incessantemente valorizada, coordenada em tempo real, que resulta em uma mobilização efetiva das competências" (p. 28). Para o autor, a inteligência coletiva se dá a partir da colaboração entre indivíduos em suas diversidades, das relações estabelecidas e de uma rede de mensagens, se configurando como um tipo de inteligência compartilhada. É o aprendizado que transforma o conhecimento pessoal de cada indivíduo, o conhecimento tácito, em conhecimento explícito, que pode ser compartilhado em dados, informações e modelos. Um aprendizado potencializado pelo uso de aplicativos em dispositivos móveis que configuram práticas de App-learning.

Tais práticas indicam que o uso crescente da tecnologia, e principalmente da internet, vem propiciando novos ambientes de aprendizagem e um significativo acesso às informações e ao conhecimento. Temos, assim, vivenciado uma época em que aprender não se restringe mais aos muros da escola, tendo a aprendizagem ganhado novos e subversivos sentidos a partir da mobilidade ubíqua. Cabe, no entanto, ressaltar o indispensável papel mediador do professor como orientador dos processos de aprendizagem constituídos nas redes digitais, tendo em vista que "nem tudo que cai na rede é peixe". 


\section{REFERÊNCIAS}

ALVES, N. Políticas e cotidianos em redes educativas e em escolas. In: XVI ENDIPE. Livro 1. Campinas: Junqueira \& Marin, 2012. p. 26 - x38. Disponível em: <http://www.infoteca.inf.br/endipe/smarty/templates/arquivos_template/ upload_arquivos/acervo/docs/0004m.pdf>. Acesso em: 01 jun. 2018.

COUTO JUNIOR, D. R. Cibercultura, juventude e alteridade: aprendendo-ensinando com o outro no Facebook. Rio de Janeiro, 2012. 133 f. Dissertação (Mestrado) - Curso de Educação, Programa de Pós-graduação em Educação, Universidade Estadual do Rio de Janeiro, Rio de Janeiro, 2012. Disponível em: <http://www.proped.pro. br/teses/teses_pdf/2010_1-646-ME.pdf>. Acesso em: 05 jan. 2016.

LEMOS, A. Cibercultura como território recombinante. In: MARTINS, C.D.; SILVA, D.C.; MOTTA, R. (Org.). Territórios Recombinantes: Arte e tecnologia / Debates e laboratórios. São Paulo: Imprensa Oficial do Estado de São Paulo, 2007. p. 35-48. Disponível em: <http://www.premiosergiomotta.org.br/diversos/d_550>. Acesso em: 28 fev. 2017.

LÉVY, P. A inteligência coletiva: por uma antropologia do ciberespaço. 4. ed. São Paulo: Loyola, 2003.

LUCENA, S.; PEREIRA, S. A. C.; OLIVEIRA, A. A. D. Redes e fluxos na iniciação à docência: o WhatsApp Messenger como espaçotempo de formação no Programa Institucional de Iniciação à Docência. In: COUTO, E.; PORTO, C.; SANTOS, E. O. (Org.). APP-LEARNING: experiências de pesquisa e formação. Salvador: Edufba, 2016. Cap. 6. p. 109-126.

OLIVEIRA, I. B.; ALVES, N. (org.). Pesquisa no/do cotidiano das escolas - sobre redes de saberes. Rio de Janeiro: DP\&A, 2001.

OLIVEIRA, C. A.; MERCADO, L. P. L. Ensino de matemática utilizando o aplicativo QRCode no contexto das tecnologias móveis. In: COUTO, E.; PORTO, C.; SANTOS, E. O. (Org.). APP-LEARNING: experiências de pesquisa e formação. Salvador: Edufba, 2016. Cap. 12. p. 211-226.

PRETTO, N.; PINTO, C. C. Tecnologias e Novas Educações. Revista Brasileira de Educação, Rio de Janeiro, v. 11, n. 31, p.19-30, jan. 2006. Quadrimestral.

SANTOS, E. O. (Entrevistado). Salto para o Futuro, 2011. Disponível em: https://tvescola.org.br/tve/saltoacervo/interview;jsessionid=BF985665EDF0D69A08E0552B4C2BA534?idInterview=8460. Acesso em: 02 set. 2018.

SANTOS, E. O. Pesquisa-Formação na Cibercultura. Santo Tirso: Whitebooks, 2014.

. A mobilidade cibercultural: cotidianos na interface educação e comunicação. Revista Em Aberto - INEP, v. 28, p. 134-148, 2015.

SANTOS, E. O.; CARVALHO, F. S. P.; PIMENTEL, M. Mediação docente online para colaboração: notas de uma pesquisa-formação na cibercultura. ETD - Educação Temática Digital, Campinas, SP, v. 18, n. 1, p. 23-42, abr. 2016. ISSN 1676-2592. Disponível em: <https://periodicos.sbu.unicamp.br/ojs/index.php/etd/article/view/8640749>. Acesso em: 30 jul. 2018. doi:https://doi.org/10.20396/etd.v18i1.8640749.

SANTOS, E. O.; MADDALENA, T. L.; ROSSINI, T. S. S. Diário hipertextual on-line de pesquisa: uma experiência com o aplicativo Evernote. In: COUTO, E.; PORTO, C.; SANTOS, E. O. (Org.). App-learning: experiências de pesquisa e formação. Salvador: Edufba, 2016. Cap. 5. p. 93-108.

SANTOS, E. O.; SANTOS, R. A tessitura do conhecimento via mídias e redes sociais da internet: notas de uma pesquisa - formação multirreferencial em um curso de especialização. Educação em Foco, Juiz de Fora, v. 18, n. 1, p.43-69, mar. 2013. Trimestral. Disponível em: 〈http://www.ufjf.br/revistaedufoco/files/2014/06/texto-2.pdf〉. Acesso em: 01 jun. 2018.

SANTOS, E. O.; WEBER, A. A criação de atos de currículo no contexto de espaços intersticiais. TECCOGS: Revista Digital de Tecnologias Cognitivas, v. 7, p. 41-60, 2013.

SANTOS, E. O.; WEBER, A. Educação e cibercultura: aprendizagem ubíqua no currículo da disciplina didática. Revista Diálogo Educacional, Paraná, v. 13, n. 38, p.285-303, jan. 2013. Quadrimestral. Disponível em: <http://www2.pucpr.br/ reol/pb/index.php/dialogo?dd1=7646\&dd99=view\&dd98=pb>. Acesso em: 10 mar. 2018. 


\section{RESUMO}

O artigo versa sobre experiências de jovens mediadas por tecnologias digitais em rede e as táticas praticadas por estes para o aprendizado do inglês. Inicialmente, são analisadas mudanças na organização da sociedade ocorridas com o surgimento e popularização dos processos comunicacionais digitais. Em seguida, são apresentadas oficinas realizadas como procedimento metodológico escolhido para o desenvolvimento do estudo. As oficinas mostraram que o trabalho com o celular e o uso de diferentes aplicativos potencializam os modos de aprender e ensinar na era da conectividade. Os achados da pesquisa revelam que mobilidade, ubiquidade e conectividade estão diretamente ligadas às formas de ensinar e aprender inglês propiciam autoria e a tessitura colaborativa de conhecimentos.

Palavras-chave: Digital em rede, dispositivos móveis, ensino de inglês.

\section{ENGLISH TEACHING ACTIVISM: LEARNING ON WEB}

\section{ABSTRACT}

The article deals with young people's experiences mediated by digital technologies and the tactics practiced by them for learning the English language. The work initially presents the changes in the society organization that have occurred with the emergence and popularization of digital communication processes. We also present some workshops as the methodological procedure chosen for the development of the study. Workshops have shown that working with mobile phones and using different applications potentiate ways of learning and teaching in the age of connectivity. The research's findings reveal that mobility, ubiquity and connectivity are directly linked to the ways of teaching and learning English provide authorship and the colaborative interwoven knowledge.

Keywords: Digital networking, mobile devices, English teaching.

\section{ACTIVISMO EN LA ENSEÑANZA DEL INGLÉS: APRENDIENDO EN RED}

\section{RESUMEN}

El artículo analiza las experiencias de los jóvenes mediadas por las tecnologías digitales en red y las tácticas practicadas por éstas para aprender inglés. Inicialmente, se analizan los cambios en la organización de la sociedad que se produjo con la aparición y popularización de los procesos de comunicación digital. Posteriormente, los talleres se presentan como un procedimiento metodológico elegido para el desarrollo del estudio. Los talleres mostraron que el trabajo con el teléfono móvil y el uso de diferentes aplicaciones potencializan las formas de aprendizaje y enseñanza en la era de la conectividad. Los resultados de la investigación revelan que la movilidad, la ubicuidad y la conectividad están directamente relacionadas con las formas de enseñar y aprender inglés, proporcionando autoría y la tesitura colaborativa del conocimiento.

Palabras clave: Redes digitales, dispositivos móviles, enseñanza del inglês.

Submetido em Agosto de 2019 Aprovado em Outubro de 2019 